\title{
An investigation on environmentally friendly biodiesel-based invert emulsion drilling fluid
}

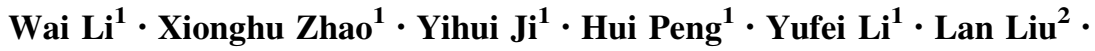 \\ Xiao Han $^{3}$
}

Received: 1 January 2015/ Accepted: 17 October 2015/Published online: 7 November 2015

(c) The Author(s) 2015. This article is published with open access at Springerlink.com

\begin{abstract}
As one blend of monoalkyl esters of fatty acids, biodiesel has a potential to serve as the external phase of drilling fluid due to its abundant sources, great safety, low toxicity, and excellent biodegradability. There are some investigations on designing of biodiesel-based drilling fluids, but most of them are about water-free system instead of emulsion system which is the most commonly used. In this paper, a biodiesel-based invert emulsion drilling fluid (BBDF) was prepared and its properties were evaluated. The results revealed that this drilling fluid has high electrical stability, acceptable rheological parameters, and satisfactory filtration property. After hot-rolling at $120{ }^{\circ} \mathrm{C}$ for $16 \mathrm{~h}$, these properties are still able to meet the operational requirements for drilling engineering. BBDF can tolerate $10 \%$ sea water, or $15 \%$ drilling solid. Due to its excellent lubricity, low toxicity, and great biodegradability, it is suitable to be used in extended reach drilling, directional drilling, or horizontal drilling. The biodiesel and emulsifier in this drilling fluid system are both produced from waste cooking oil. This may promote the waste recycled and utilized in a more effective and integral way. Some economic analysis and discussion were also made, indicating the cost
\end{abstract}

W. Li and X. Zhao contributed equally to this work.

Wai Li

80846411@qq.com

1 State Key Laboratory of Petroleum Resources and Prospecting, China University of Petroleum (Beijing), 18\# Fuxue Road, Changping, Beijing 102249, China

2 College of Chemistry and Chemical Engineering, Xinjiang University, Urumqi 830046, China

3 Beijing LDS Technology Co. Ltd., Beijing 100022, China feasibility of BBDF. Evidently, biodiesel-based drilling fluid has a considerable value for further investigation.

Keywords Biodiesel $\cdot$ Drilling fluid $\cdot$ Stability $\cdot$ Invert emulsion $\cdot$ Emulsifier

\author{
List of symbols \\ AV Apparent viscosity (mPa.s) \\ CFPP Cold filter plugging point \\ $\mathrm{COF}$ Coefficients of friction, dimensionless \\ $\mathrm{EC}_{50}$ Effective concentration $50 \%(\mathrm{mg} / \mathrm{L})$ \\ $K \quad$ Consistency index in the Herschel-Bulkley model \\ $\left(\mathrm{Pa} \cdot \mathrm{s}^{n}\right)$ \\ $\mathrm{LC}_{50}$ Lethal concentration $50 \%(\mathrm{mg} / \mathrm{L})$ \\ $n \quad$ Shear-thinning index in the Herschel-Bulkley \\ model, dimensionless \\ PP Pour point $\left({ }^{\circ} \mathrm{C}\right)$ \\ $\mathrm{PV} \quad$ Plastic viscosity (mPa.s) \\ $R^{2} \quad$ Goodness of fit, dimensionless \\ YP Yield point $(\mathrm{Pa})$ \\ $\dot{\gamma} \quad$ Shear rate $\left(\mathrm{s}^{-1}\right)$ \\ $\tau \quad$ Shear stress $(\mathrm{Pa})$ \\ $\tau_{0} \quad$ Yield stress in the Herschel-Bulkley model (Pa)
}

\section{Introduction}

With the rapid development of drilling technology, structures of the wells drilled are becoming more complex and the operational environments harsher. Water-based drilling fluids (WBDFs) have difficulty in meeting the requirements for coping with these complicated situations (Zhang 1998; Li et al. 2005). Oil-based drilling fluids (OBDFs) offer superior hole stability, thinner filter cake, excellent lubricity, and less 
risk of stuck pipe. For these reasons, operators prefer using OBDFs for highly difficult drilling (Yan 2001). However, conventional OBDFs (diesel-based or mineral oil-based) have two drawbacks which cannot be ignored: One is their high costs, and the other is their adverse impacts on the environment (Friedheim and Patel 1999; James et al. 1999). Since 1990s, environmental laws and regulations in many countries have been becoming stricter. This reduced the usage frequency of conventional OBDFs sharply (Candler et al. 1993). As an appropriate response to this, ester-based drilling fluids (EBDF) were developed. Not only can they provide operational performances like conventional OBDFs, but also they have low toxicity and good biodegradability. In some areas, EBDF can be discharged without any treatment, which is very meaningful for marine drilling (Neff 2005). Ester is first field trialed offshore Norway and has been used to drill hundreds of wells since that time (Peresich et al. 1991). Nonetheless, as one type of synthetic materials, ester is generally expensive in comparison to diesel and mineral oils (Friedheim 1997). High cost restricts the development of EBDF seriously (Caenn and Chillingar 1996).

Biodiesel comprises monoalkyl esters of fatty acids derived from natural and renewable sources, such as animal fats and vegetable oils. It was considered as a promising alternative to the conventional petrodiesel (ASTM D6751 2009). Biodiesel has a potential to serve as a base fluid for drilling fluids, since it possesses all the advantages of conventional esters. Feedstock of biodiesel is abundant and renewable, such as Jatropha curcas oil (Mohibbe Azam et al. 2005), Pongamia pinnata (Srivastava and Verma 2008), and rice bran (Sinha et al. 2008). This assures the source of biodiesel steady. Additionally, it would be of great significance for waste management and recycling, if the biodiesel produced from soapstock (Haas et al. 2003) or waste cooking oil (Predojević 2008) can be used as the external phase of drilling fluid.

Recently, the world biodiesel production increased quickly. In consequence, the biodiesel industry is confronted with the problem of excess production capacity. Rapid growth of production lowers the price of biodiesel to some degree. For another, biodiesel cannot replace petrodiesel completely yet (DeOliveira et al. 2006; Knothe 2008). Therefore, designing a drilling fluid system based on biodiesel would not only provide a cost-effective working fluid for drilling engineers, but also extend the application of biodiesel meanwhile.

Developing biodiesel-based drilling fluids has been concerned for some time in China, and a few relevant papers were presented since 2012 (Wang et al. 2012; Yang et al. 2013). Unfortunately, authors of these papers do not describe the biodiesels they used in detail. Also, the drilling fluids reported in these papers were water-free drilling fluids instead of brine-in-biodiesel (W/O, or referred as "invert") emulsion system which is the most common in drilling operations. It is well-known that there are certain restrictions on the application of water-free drilling fluids owing to their high cost and too low viscosity. Hence, invert biodieselbased drilling fluid should be investigated for further application of biodiesel.

In this work, a kind of biodiesel produced from waste cooking oil was used to prepare the biodiesel-based invert emulsion drilling fluid (BBDF). On the basis of the stable biodiesel emulsion, a BBDF system was obtained and its properties, including electrical stability, rheological parameters, filtration property, thermal stability, contaminant tolerance, lubricity, shale inhibition, ecotoxicity, and biodegradability, were evaluated. Some discussion on the results was given and a novel effective emulsifier produced from waste cooking oil for BBDF was also introduced.

\section{Experimental}

\section{Preparation of biodiesel}

The preparation process is based on the transesterification reaction (Moser 2011) using waste cooking oil as feedstock, shown in Fig. 1.

\section{Basic properties of biodiesel}

Some basic properties of the biodiesel were tested according to relevant specifications as shown in Table 1 (ECN EN14214 2003; ASTM D97 2002; ASTM D6751 2009; ASTM D6371 2010).

\section{Wettability evaluation}

In order to compare the wettabilities of different fluids on the drilling tool steel, surface tensions of some fluids (including water, white oil, petrodiesel, soybean oil and biodiesel) were determined by a BZY-1 surface tension meter (Hengping Instrument Factory) which employs the Wilhelmy plate principle. Their contact angles on a smooth, clean surface of G105 steel (commonly used for drill pipes) in the air were also measured by an optical contact angle tester (Xiamen Chongda Intelligent Technology Co. Ltd.), respectively.

\section{Drilling fluid formulations}

The biodiesel-based drilling fluid (BBDF) was prepared as the following formulation $(O / W=80 / 20)$.

Biodiesel $(280 \mathrm{~mL})+$ Emulsifier $1(14 \mathrm{~g})+20 \mathrm{wt} \%$ $\mathrm{CaCl}_{2}$ solution $(70 \mathrm{~mL})+$ organophilic clay $(10.5 \mathrm{~g})+$ lime $(1.75 \mathrm{~g})+$ filtration reducer $(14 \mathrm{~g})+$ Emulsifier 2 $(3.5 \mathrm{~g})+$ barite to required density. 


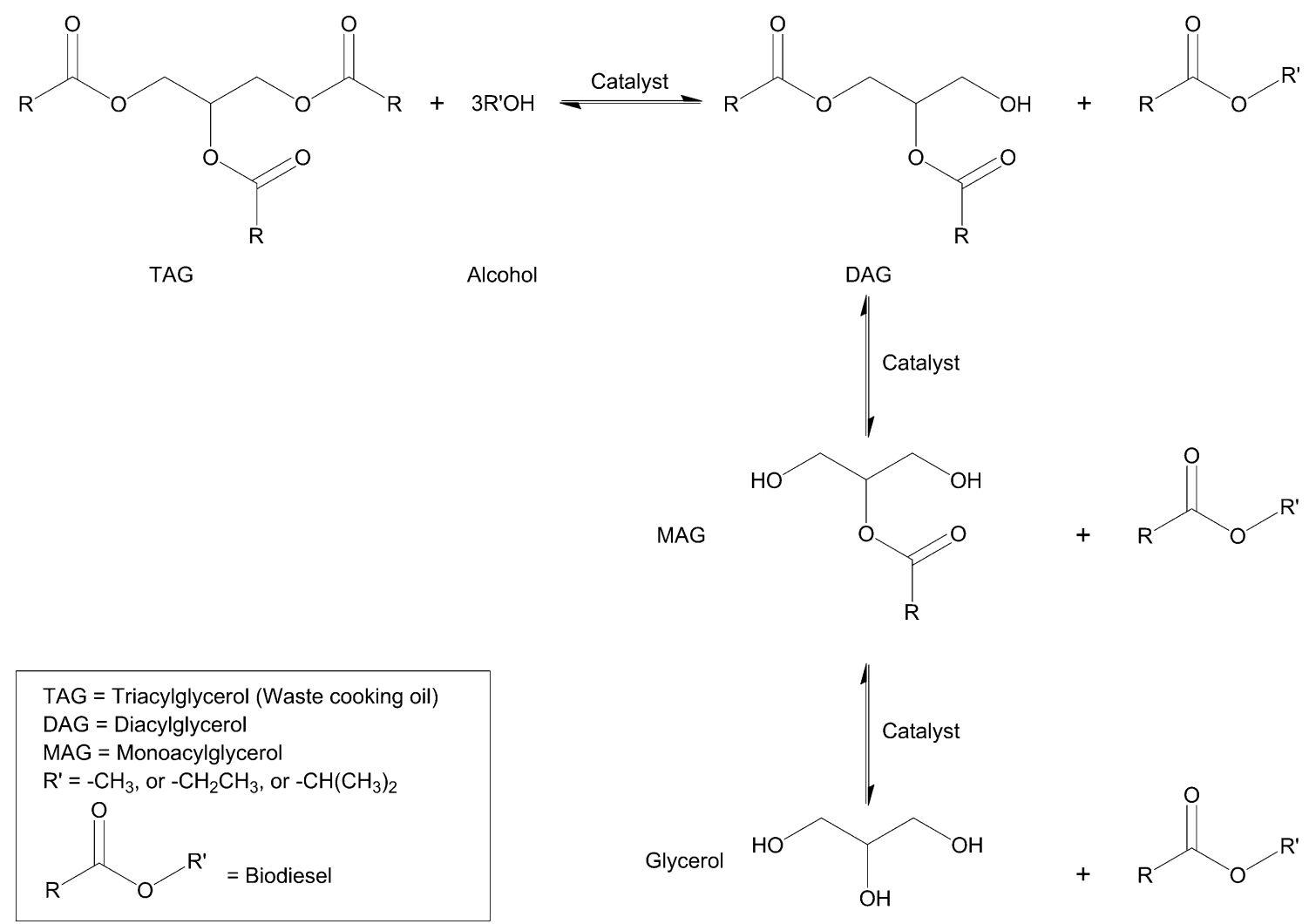

Fig. 1 Transesterification of triacylglycerols to produce fatty acid alkyl esters (biodiesel)

Table 1 Basic properties of biodiesel

\begin{tabular}{lllll}
\hline Properties & Units & Waste cooking oil biodiesel & Petrodiesel (0\#) & Test protocol \\
\hline Appearance & - & Light, yellow, viscous liquid & Light, yellow, viscous liquid & - \\
Density, $15{ }^{\circ} \mathrm{C}$ & $\mathrm{g} / \mathrm{cm}^{3}$ & 0.87 & 0.86 & EN 14214 \\
Kinematic viscosity, $40{ }^{\circ} \mathrm{C}$ & $\mathrm{mm}^{2} / \mathrm{s}$ & 4.2 & 3.5 & ASTM D6751 \\
Flash point (closed cup) & ${ }^{\circ} \mathrm{C}$ & 166 & 78 & ASTM D6751 \\
Pour point & ${ }^{\circ} \mathrm{C}$ & 3 & 4 & ASTM D97 \\
Cold filter plugging point & ${ }^{\circ} \mathrm{C}$ & -4 & 3 & ASTM D6371 \\
Sediment & $\%$ & None & None & ASTM D6751 \\
Water content & $\%$ & None & $<0.1$ & ASTM D6751 \\
Sulfur & $\%$ & None & $<45$ & ASTM D6751 \\
Copper strip corrosion $\left(50{ }^{\circ} \mathrm{C}, 3 \mathrm{~h}\right)$ & $\mathrm{Ranking}$ & $1 \mathrm{a}$ & $4 \mathrm{a}$ & ASTM D6751 \\
Cetane number & - & 49.6 & 46 & ASTM D6751 \\
Acid value & $\mathrm{mg} \mathrm{KOH} / \mathrm{g}$ & 0.13 & 5 & ASTM D6751 \\
Free glycerin & $\%$ & 0.01 & - & ASTM D6751 \\
Total glycerin & $\%$ & 0.03 & ASTM D6751 \\
Oxidation stability (oil stability index at $\left.110{ }^{\circ} \mathrm{C}\right)$ & $\mathrm{h}$ & $>6$ & ASTM D6751 \\
\hline
\end{tabular}

Similarly, a petrodiesel-based invert emulsion drilling fluid (OBDF, $O / W=80 / 20$ ) was prepared for comparison as the following formulation.

Petrodiesel (0\#, $280 \mathrm{~mL})+$ Emulsifier $3(10.5 \mathrm{~g})+$ $20 \mathrm{wt} \% \mathrm{CaCl}_{2}$ solution $(70 \mathrm{~mL})+$ organophilic clay
$(10.5 \mathrm{~g})+$ lime $(7.0 \mathrm{~g})+$ filtration reducer $(14 \mathrm{~g})+$ Emulsifier $4(5.25 \mathrm{~g})+$ barite to required density.

The information of chemicals used for fluid preparation is listed in Table 2. Here, Emulsifier 1 and Emulsifier 2 in the BBDF were developed in the lab. We will discuss them 
Table 2 Chemicals used in the drilling fluids

\begin{tabular}{|c|c|c|c|}
\hline Name & Commercial name & Supplier & Essential component \\
\hline Emulsifier 1 & - & Prepared in the lab & Fatty alkanolamides \\
\hline Emulsifier 2 & - & Prepared in the lab & Alkyl sulfonate \\
\hline Emulsifier 3 & INVERMUL & BAROID & Aliphatic amine \\
\hline Emulsifier 4 & EZMUL & BAROID & Poly (fatty acid amides) \\
\hline Organophilic clay & VG-69 & M-I SWACO & $\begin{array}{l}\text { Quaternary ammonium } \\
\text { salt-treated bentonite }\end{array}$ \\
\hline Filtration Reducer 1 & VERSATROL & M-I SWACO & Polyacrylate \\
\hline Filtration Reducer 2 & FB-MOTEX & Xinxiang Fubang Technology Co., Ltd & Humic acid amide \\
\hline $\mathrm{CaCl}_{2}$ & $\mathrm{CaCl}_{2}$ & Sigma-Aldrich & $\mathrm{CaCl}_{2}$ \\
\hline Lime & $\mathrm{Ca}(\mathrm{OH})_{2}$ & Sigma-Aldrich & $\mathrm{Ca}(\mathrm{OH})_{2}$ \\
\hline Barite & Barite & $\begin{array}{l}\text { Beijing Oilchemleader Science and } \\
\text { Technic Development Co., Ltd }\end{array}$ & $\mathrm{BaSO}_{4}(300$ mesh $)$ \\
\hline
\end{tabular}

in the section "Emulsifier package for biodiesel-based drilling fluid." Other chemicals were purchased commercially.

For all of the drilling formulations, the agents were added slowly. The systems were stirred fully by a homogenizer at the shear rate of $11,000 \mathrm{rpm}$. Then the drilling fluids were allowed to stand still in the ambient temperature for $24 \mathrm{~h}$.

\section{Property evaluation}

For both BBDF and OBDF, their rheological parameters including apparent viscosity (AV), plastic viscosity (PV), yield point (YP), YP/PV, and gel strength; API filtrate volume; and electrical stabilities (ESs) without/after hotrolling $\left(120^{\circ} \mathrm{C}, 16 \mathrm{~h}\right)$ were measured in the light of the standard test recommended by API RP 13B-2 (2005).

The rheograms (i.e., plots of shear stress versus shear rate) of BBDF and OBDF under different temperatures (50, 80,100 , and $120^{\circ} \mathrm{C}$ ) were determined by using a Haake RS $150 \mathrm{H}$ rheometer. During the tests, each drilling fluid sample experienced hot-rolling $\left(120^{\circ} \mathrm{C}, 16 \mathrm{~h}\right)$ and fully pre-shearing (11,000 rpm, $10 \mathrm{~min})$. Then the shear stresses under various shear rates were measured. For each data point, the shearing imposed on the sample lasts $2 \mathrm{~min}$ in order that the steady-state can be achieved. The shear rates investigated in a single rheogram are in the range of $0.1-1000 \mathrm{~s}^{-1}$ and the down-sweep mode was used.

Contamination tests on the unweighted BBDF were conducted. Different amounts of sea water and shale powder (as drilling solid) were added into BBDF respectively, and the properties of the drilling fluid after hotrolling were determined to evaluate the contaminant tolerance of BBDF.

The lubricities of the drilling fluids without/after hotrolling $\left(120^{\circ} \mathrm{C}, 16 \mathrm{~h}\right)$, characterized by coefficients of friction (COFs), were measured using a Fann Model 212 extreme pressure lubricity tester (Caenn et al. 1988).

The shale inhibition test was carried out by a shale dilatometer (CPZ-II). With time elapsed, the swelling rates of shale cuttings caused by the filtrate fluids of BBDF, $\mathrm{OBDF}$, and deionized water were tested, respectively, for comparison.

In order for evaluating the ecotoxicity of BBDF, the marine algae growth inhibition test was performed according to $72 \mathrm{~h}$ marine phytoplankton $\mathrm{EC}_{50}$ (effective concentration $50 \%$ ) test (ISO 10253 2006), using alga Skeletonema costatum. The acute lethal toxicity test was carried out according to $48 \mathrm{~h} \mathrm{LC}_{50}$ test (ISO 14669 1999) using Arcatia tonsa.

The biodegradability test was performed according to the standard method OECD 301D Closed Bottle Test (1993). The dissolved oxygen of the test solution ( $2 \mathrm{mg}$ drilling fluid in $1 \mathrm{~L}$ nutrient medium, inoculated with microorganisms, and kept in a completely full, closed bottle in dark at ambient temperature) over a 28-days period was determined. Then the percentage of biodegradation can be expressed by theoretical oxygen demand. The percentage of biodegradation-time curves for BBDF and OBDF was plotted.

\section{Results and discussion}

\section{Basic properties of biodiesel}

Table 1 shows some basic properties of waste cooking oil biodiesel and petrodiesel (0\#). It is indicated that the densities of these two oils are similar. The flash point of the biodiesel is significantly higher than that of petrodiesel, meaning that biodiesel has better fire safety than petrodiesel. There is no sulfide and aromatic material in the 
biodiesel, thereby it is low-toxic and non-fluorescent. Acid value and glycerin (including glycerol, mono-, di-, and triacylglycerols) content are relevant to kinematic viscosity and low-temperature operability of biodiesel (Knothe 2006; Moser 2011; Knothe and Steidley 2005). Herein the biodiesel selected has an acceptable acid value and low glycerin content. The oil stability index of the biodiesel is also qualified ( $>6 \mathrm{~h}$ ). This assures a half-year shelf life of the biodiesel. The pour point (PP) and the cold filter plugging point (CFPP) of the biodiesel are both near to the petrodiesel, and thus, the two kinds of oils have similar low-temperature operability. The kinematic viscosity of biodiesel shows a higher value than that of petrodiesel, whereas the adverse effect on its rheology can be minimized by appropriate design of the drilling fluid formulation. In brief, the biodiesel possesses basic properties for a base fluid for drilling, particularly for its high flash point, low toxicity, and no fluorescence.

\section{Wettability evaluation}

The surface tensions and contact angles on the steel G105 of different fluids are illustrated in Fig. 2. Compared with other three oily materials, the biodiesel has a low surface tension and a small contact angle on the G105 steel. These imply that the biodiesel has a strong tendency to adhere onto the steel and it is not easy to fall off. This is naturally beneficial to form a physisorbed film of biodiesel molecules for lubrication.

\section{Electrical stability and rheological properties}

Electrical stabilities and rheological properties of BBDF and OBDF (without hot-rolling) are shown in Table 3. Table 4 gives the ESs and rheological parameters of BBDF and OBDF after hot-rolling $\left(120^{\circ} \mathrm{C}\right.$ for $\left.16 \mathrm{~h}\right)$. It can be seen that the PVs of these two fluids both increased to some

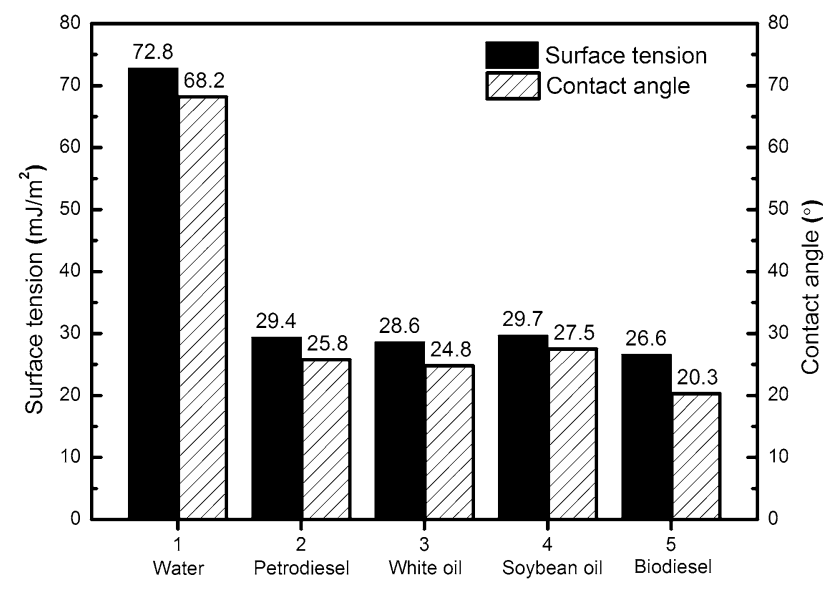

Fig. 2 Wettabilities of biodiesel and some other oily materials degree after hot-rolling while the YPs reduced. Overall, the sensitivity of viscosity of BBDF is larger than OBDF. That is, the viscosity of $\mathrm{BBDF}$ is lower than that of $\mathrm{OBDF}$ without hot-rolling, but higher than OBDF after high-temperature treatment. This may be ascribed to the difference of the affinities of the organophilic clay to these two oils. Another possible reason may be part of biodiesel would be hydrolyzed under the high temperature, producing some insoluble calcium soap (Amin et al. 2010). Therefore, it is recommended that the lime content in BBDF should be controlled strictly in order to avoid severe hydrolysis of biodiesel. However, the rheological parameters of BBDF are still acceptable according to API RP 13B-2.

To understand the rheological behavior of BBDF in depth, the rheograms of BBDF and OBDF under different temperatures were plotted in double logarithmic coordinate systems, as shown in Fig. 3. Furthermore, these curves were fitted by the Herschel-Bulkley model which is very commonly employed in the rheological studies on drilling fluids because of its high accuracy and explicit meanings of parameters (Jason 2007):

$\tau=\tau_{0}+K \dot{\gamma}^{n}$

where $\tau$ is the shear stress $(\mathrm{Pa}) ; \tau_{0}$ is the yield stress $(\mathrm{Pa}) ; K$ is the consistency index $\left(\mathrm{Pa} \cdot \mathrm{s}^{n}\right) ; \dot{\gamma}$ is the shear rate $\left(\mathrm{s}^{-1}\right)$; and $n$ is the shear-thinning index, dimensionless. The fitting results, including the rheological parameters and the goodnesses of fit $\left(R^{2} \mathrm{~s}\right)$, are presented in Table 5 .

It can be seen that the general tendencies of rheograms of BBDF in different temperatures resemble those of OBDF. The Herschel-Bulkley model can fit these rheological data very well, which is demonstrated by the high values of $R^{2}$. Nevertheless, there are still some differences between the two fluids as follows:

- The $\tau$ of BBDF under $50{ }^{\circ} \mathrm{C}$ is higher than that of OBDF, while the situation is opposite when the temperature exceeds $80{ }^{\circ} \mathrm{C}$. The four curves of BBDF are more scattered than those of OBDF, indicating that the shear stress of BBDF is more sensitive to temperature than $\mathrm{OBDF}$.

- Below $100{ }^{\circ} \mathrm{C}$, the $\tau_{0}$ of BBDF is higher than OBDF. When the temperature is above $100{ }^{\circ} \mathrm{C}$, the $\tau_{0} \mathrm{~s}$ of the two fluids are comparable. This implies that BBDF has a good ability to carry the cuttings out from the wellbore (at least no weaker than the carrying ability of OBDF).

- The comparisons of $K$ and $n$ of these two fluids are kind of complex. In general, $K$ of BBDF is lower than OBDF, and the $n$ s of the two fluids did not appear much different.

Evidently, the BBDF is qualified for the drilling operations where temperatures are not more than $120^{\circ} \mathrm{C}$ owing 
Table 3 Electrical stabilities and rheological properties of BBDF and OBDF (without hot-rolling)

\begin{tabular}{llllll}
\hline Properties & Units & BBDF (unweighted) & BBDF (weighted) & OBDF (unweighted) & OBDF (weighted) \\
\hline Density & $\mathrm{g} / \mathrm{cm}^{3}$ & 1.026 & 1.304 & 1.020 & 1.315 \\
ES & $\mathrm{V}$ & 1540 & 2000 & 1215 & 2000 \\
$\mathrm{AV}$ & $\mathrm{mPa} \cdot \mathrm{s}$ & 23.5 & 39.5 & 26.0 & 42.0 \\
$\mathrm{PV}$ & $\mathrm{mPa} \cdot \mathrm{s}$ & 13.5 & 29.0 & 15.0 & 30.0 \\
YP & $\mathrm{Pa}$ & 10.0 & 10.5 & 11.0 & 12.0 \\
YP/PV & $\mathrm{Pa} / \mathrm{mPa} \cdot \mathrm{s}$ & 0.741 & 0.362 & 0.733 & 0.400 \\
Gel strength $(10 \mathrm{~s} / 10 \mathrm{~min})$ & Reading/reading & $9.0 / 10.5$ & $10.0 / 11.0$ & $11.0 / 11.5$ & $12.5 / 12.5$ \\
\hline
\end{tabular}

Test temperature: $50^{\circ} \mathrm{C}$

Table 4 Electrical stabilities and rheological properties of BBDF and OBDF after hot-rolling $\left(120^{\circ} \mathrm{C}, 16 \mathrm{~h}\right)$

\begin{tabular}{llllll}
\hline Properties & Units & BBDF (unweighted) & BBDF (weighted) & OBDF (unweighted) & OBDF (weighted) \\
\hline Density & $\mathrm{g} / \mathrm{cm}^{3}$ & 1.026 & 1.304 & 1.020 & 1.315 \\
ES & $\mathrm{V}$ & 2000 & 2000 & 1100 & 1420 \\
$\mathrm{AV}$ & $\mathrm{mPa} \cdot \mathrm{s}$ & 34.5 & 53.5 & 33.0 & 49.0 \\
$\mathrm{PV}$ & $\mathrm{mPa} \cdot \mathrm{s}$ & 26.0 & 42.0 & 25.0 & 38.5 \\
YP & $\mathrm{Pa}$ & 8.5 & 11.5 & 8.0 & 10.5 \\
YP/PV & $\mathrm{Pa} / \mathrm{mPa} \cdot \mathrm{s}$ & 0.327 & 0.274 & 0.320 & 0.272 \\
Gel strength $(10 \mathrm{~s} / 10 \mathrm{~min})$ & Reading/reading & $8.5 / 10.5$ & $12.0 / 14.5$ & $8.5 / 13.0$ & $11.5 / 15.5$ \\
\hline
\end{tabular}

Test temperature: $50^{\circ} \mathrm{C}$
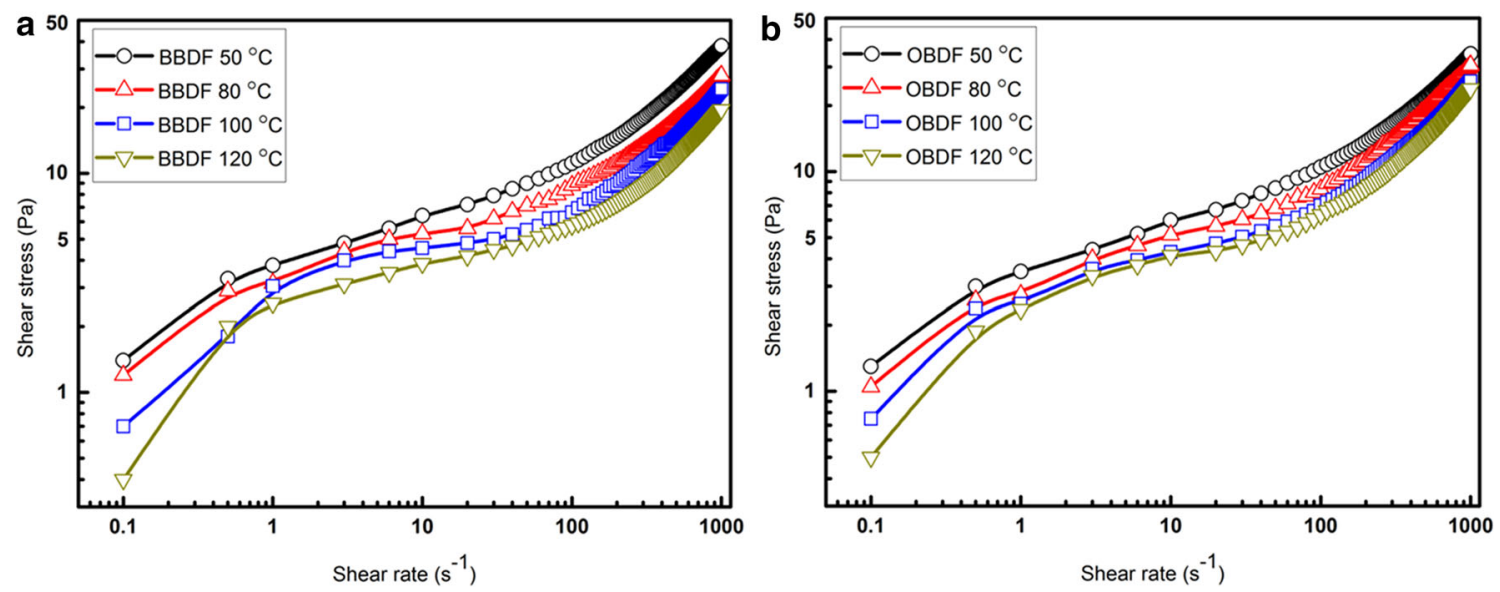

Fig. 3 Rheograms of BBDF and OBDF under different temperatures (a: BBDF; b: OBDF)

to its behavior similarity to OBDF. Nonetheless, it should be pointed out that BBDF indeed exhibits more viscous than OBDF under low temperatures, which probably restricts its application in some occasions (e.g., deepwater or cold environment). Relevant studies aiming to solve this problem, such as seeking a suitable rheological modifier, are underway.

There are two reasons which cause the discrepancy of temperature sensitivity of these fluids: One is the difference in the viscosity-temperature characteristics of the base oils, i.e., biodiesel and petrodiesel. The effects of chain length, double bond number, cis-trans isomerism, and type of ester head groups on the viscosity-temperature characteristic of biodiesel (which naturally influences the viscositytemperature characteristic of BBDF) are well-documented in literature (Moser 2011; Knothe and Steidley 2005). Another reason is that there are differences of molecular interactions between the base oil and all sorts of chemicals in the drilling fluids. Even if identical additives are used in BBDF and OBDF, the values of rheological parameters and 
Table 5 Goodnesses of fit $\left(R^{2} \mathrm{~s}\right)$ for rheological data given in Fig. 3 with the Herschel-Bulkley model (calculated by the LevenbergMarquardt algorithm)

\begin{tabular}{lllll}
\hline Sample & $\tau_{0}(\mathrm{~Pa})$ & $K\left(\mathrm{~Pa} \cdot \mathrm{s}^{n}\right)$ & $n$ & $R^{2}$ \\
\hline BBDF $\left(50{ }^{\circ} \mathrm{C}\right)$ & 4.588 & 0.190 & 0.747 & 0.9974 \\
BBDF $\left(80^{\circ} \mathrm{C}\right)$ & 4.017 & 0.129 & 0.754 & 0.9959 \\
BBDF $\left(100^{\circ} \mathrm{C}\right)$ & 3.346 & 0.076 & 0.809 & 0.9956 \\
$\operatorname{BBDF}\left(120^{\circ} \mathrm{C}\right)$ & 3.155 & 0.039 & 0.870 & 0.9937 \\
OBDF $\left(50^{\circ} \mathrm{C}\right)$ & 4.186 & 0.210 & 0.716 & 0.9970 \\
OBDF $\left(80^{\circ} \mathrm{C}\right)$ & 3.419 & 0.146 & 0.755 & 0.9978 \\
OBDF $\left(100^{\circ} \mathrm{C}\right)$ & 3.374 & 0.069 & 0.833 & 0.9961 \\
OBDF $\left(120^{\circ} \mathrm{C}\right)$ & 3.155 & 0.052 & 0.862 & 0.9957 \\
\hline
\end{tabular}

viscosity characteristics of the two fluids would be different from one to another. These facts mean that we should select a biodiesel having suitable rheological properties and develop/choose eligible additives for designing a highperformance BBDF.

As for ES data, both of the fluids are quite stable at $50{ }^{\circ} \mathrm{C}$. The ES of OBDF decreased to some degree after hot-rolling, although the value was still acceptable. On the other hand, BBDF remained its high electrical stability. This demonstrates that BBDF is able to meet the operational requirements for drilling engineering at $120{ }^{\circ} \mathrm{C}$. The addition of barite can increase the ES and PV significantly. The possible mechanism for this phenomenon may be that the barite particles can move onto the oil/water interface under the effect of emulsifiers, forming a "pickering emulsion" enhancing the stability of the whole system (Becher 1965).

\section{API filtrate volume}

Figure 4 reveals the API filtrate volumes of BBDF and OBDF without/after hot-rolling. From this figure, it can be known that BBDF has a satisfactory filtration property (API filtrate volumes $<10 \mathrm{~mL}$ ). Thermal treatment reduces the API filtrate volume of BBDF slightly while the situation for OBDF is opposite. It should be pointed out that there is no water phase in the filtrate fluid of BBDF, demonstrating the great stability of this system.

Also, the relationships between filtrate volume and filtration time for these two drilling fluids (after hot-rolling) were investigated. Figure 5 is the filtrate volume-time curves under different temperatures and pressures for unweighted BBDF and OBDF. Figure 6 illustrates the filtrate volume-time curves under different temperatures and pressures for the weighted fluids. In general, the filtrate volume of BBDF is slightly higher than that of OBDF, but still acceptable. As a reference point recognized by the current drilling industry, a filtrate volume below $10 \mathrm{~mL}$ in $30 \mathrm{~min}$ is commonly eligible for the drilling operation. In some occasions, this limitation can be loosened to $15 \mathrm{~mL}$

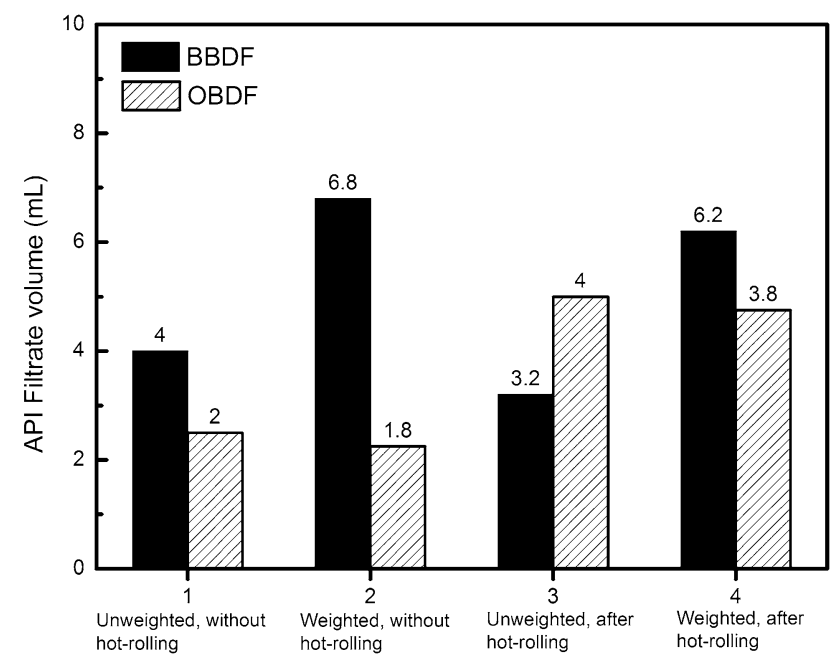

Fig. 4 API filtrate volumes of BBDF and OBDF without/after hotrolling (test condition for the fluids without hot-rolling: $20{ }^{\circ} \mathrm{C}, 0.1$ $\mathrm{MPa}$; for the fluids after hot-rolling: $120^{\circ} \mathrm{C}, 3.5 \mathrm{MPa}$ )

(Yang et al. 2013). The addition of barite seems to decrease the filtrate volume of OBDF more or less while it does an opposite effect on BBDF, indicating that barite particles can influence the formation of filter cake to some degree. This phenomenon needs to be studied more in detail.

\section{Contamination study}

The properties of unweighted BBDF with different amounts of sea water after hot-rolling are shown in Table 6. It can be known that BBDF can tolerate $10 \%$ of sea water (vol/vol). If more than $10 \%$ sea water invades into the system, the API filtrate volume will be unacceptable $(>15 \mathrm{~mL})$. Table 7 indicates the situations of BBDF with different amounts of shale powder (drilling solid). The tolerance limit for drilling solid is $15 \%$ (wt/vol). If more drilling solid exists in the system, the PV would become too high $(>50 \mathrm{mPa} \cdot \mathrm{s})$. The contaminant tolerance of BBDF can meet the requirements of engineering.

\section{Lubricity}

The COFs of BBDF and OBDF without/after hot-rolling are illustrated in Fig. 7. Obviously, BBDF has lower COF than that of OBDF regardless of hot-rolling or not. Excellent lubricity is a huge advantage of BBDF. This means BBDF is suitable to be used in extended reach drilling, directional drilling, or horizontal drilling.

The great lubricity of BBDF may be ascribed as follows: (1) Physisorption. Compared to the inert non-polar oils (e.g., petrodiesel), the biodiesel molecules possess a certain polarity, which makes the molecules physisorbed on the charged metal surfaces by Van der Waals force more easily. 

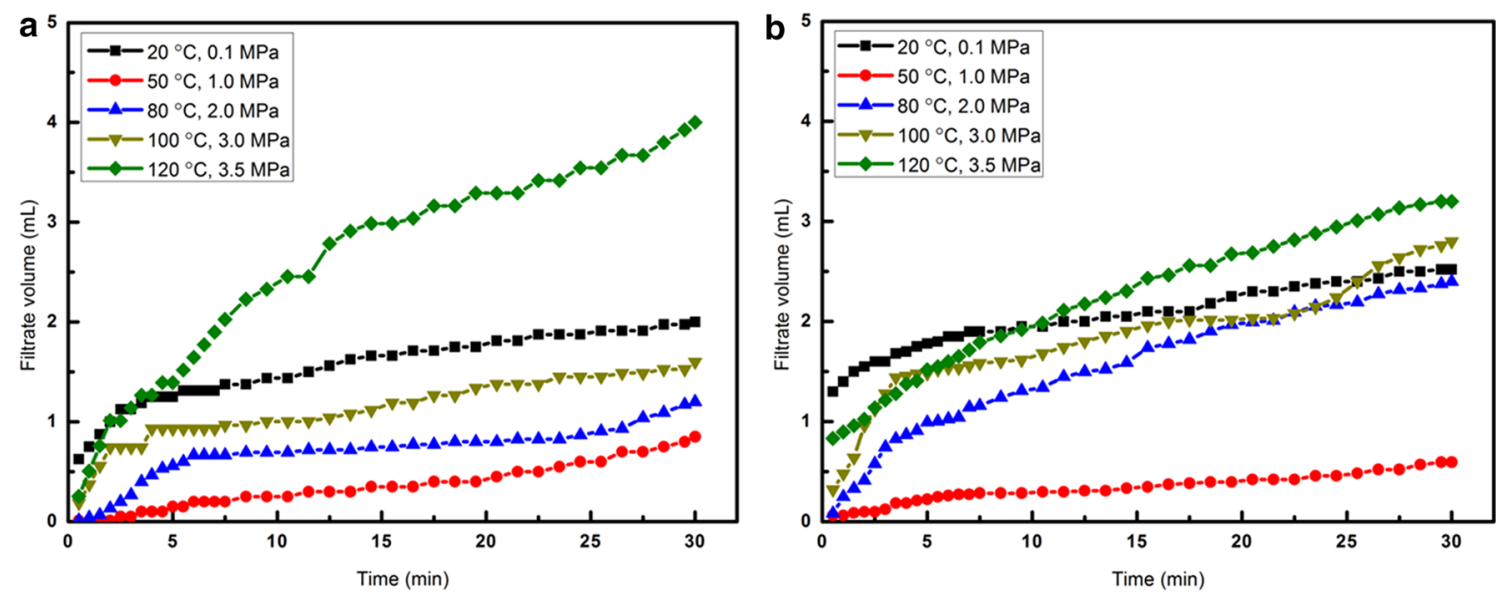

Fig. 5 Filtrate volume-time curves under different temperature and pressure for unweighted BBDF and OBDF (a: BBDF; b: OBDF)
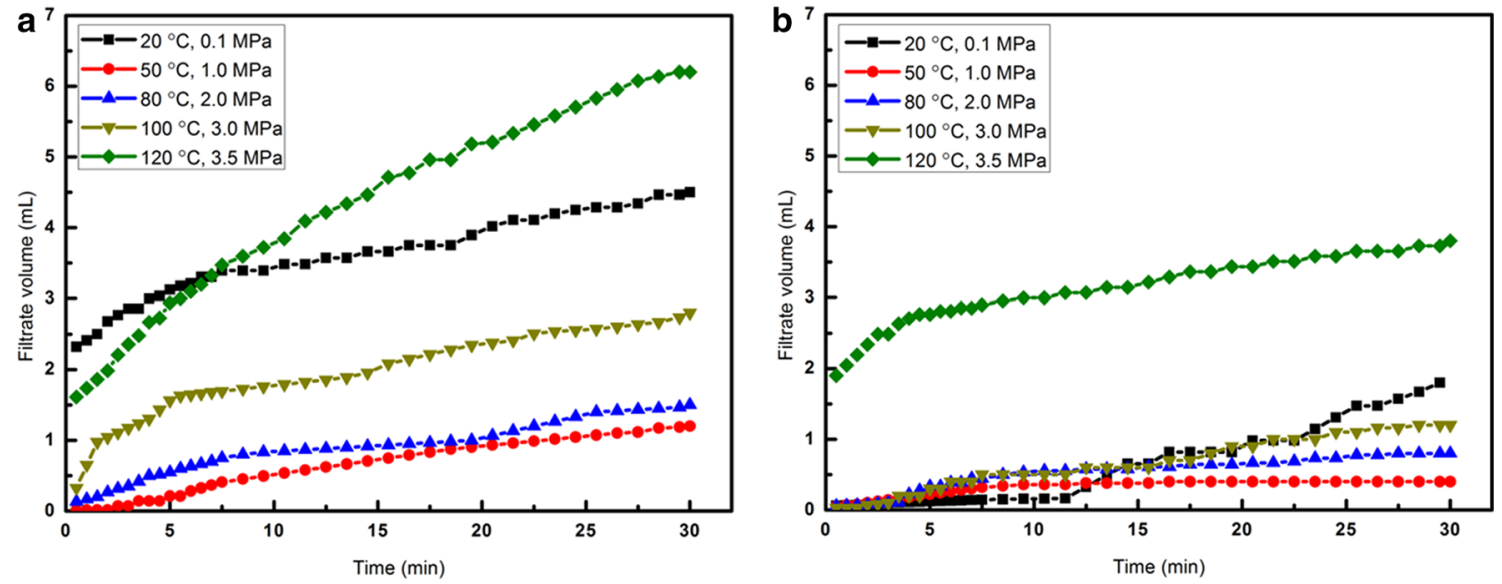

Fig. 6 Filtrate volume-time curves under different temperature and pressure for weighted BBDF and OBDF (a: BBDF; b: OBDF)

Table 6 Contamination study on unweighted BBDF: sea water (after hot-rolling at $120{ }^{\circ} \mathrm{C}$ for $16 \mathrm{~h}$ )

\begin{tabular}{lcccccc}
\hline $\begin{array}{l}\text { Amount of sea } \\
\text { water }(\mathrm{vol} / \mathrm{vol}, \%)\end{array}$ & ES $(\mathrm{V})$ & AV $(\mathrm{mPa} \cdot \mathrm{s})$ & PV $(\mathrm{mPa} \cdot \mathrm{s})$ & YP (Pa) & $\begin{array}{l}\text { Gel strength }(10 \mathrm{~s} / 10 \mathrm{~min}, \\
\text { reading/reading) }\end{array}$ & $\begin{array}{l}\text { Filtrate volume } \\
\left(120{ }^{\circ} \mathrm{C}, 3.5 \mathrm{MPa}\right)\end{array}$ \\
\hline 0 & 2000 & 34.5 & 26.0 & 8.5 & $8.5 / 10.5$ & 6.8 \\
5 & 1580 & 44.0 & 32.0 & 12.0 & $10.0 / 11.0$ & 9.8 \\
10 & 1160 & 52.5 & 39.0 & 13.5 & $12.0 / 12.5$ & 13.2 \\
15 & 710 & 62.5 & 47.0 & 15.5 & $13.0 / 13.5$ & 17.4 \\
\hline
\end{tabular}

Table 7 Contamination study on unweighted BBDF: drilling solid (after hot-rolling at $120{ }^{\circ} \mathrm{C}$ for $16 \mathrm{~h}$ )

\begin{tabular}{llllccc}
\hline $\begin{array}{l}\text { Amount of sea water } \\
(\text { vol/vol \%) }\end{array}$ & ES (V) & AV (mPa.s) & PV (mPa.s) & YP (Pa) & $\begin{array}{l}\text { Gel strength (10 s/10 min, } \\
\text { reading/reading) }\end{array}$ & $\begin{array}{l}\text { Filtrate volume } \\
\left(120{ }^{\circ} \mathrm{C}, 3.5 \mathrm{MPa}\right)\end{array}$ \\
\hline 0 & 2000 & 34.5 & 26.0 & 8.5 & $8.5 / 10.5$ & 6.8 \\
5 & 2000 & 41.0 & 32.0 & 9.0 & $8.0 / 10.0$ & 5.8 \\
10 & 1960 & 47.0 & 37.0 & 10.0 & $8.5 / 11.0$ & 8.2 \\
15 & 1880 & 55.5 & 43.0 & 12.5 & $11.0 / 13.0$ & 10.0 \\
20 & 1650 & 65.5 & 52.0 & 13.5 & $11.0 / 12.0$ & 14.8 \\
\hline
\end{tabular}




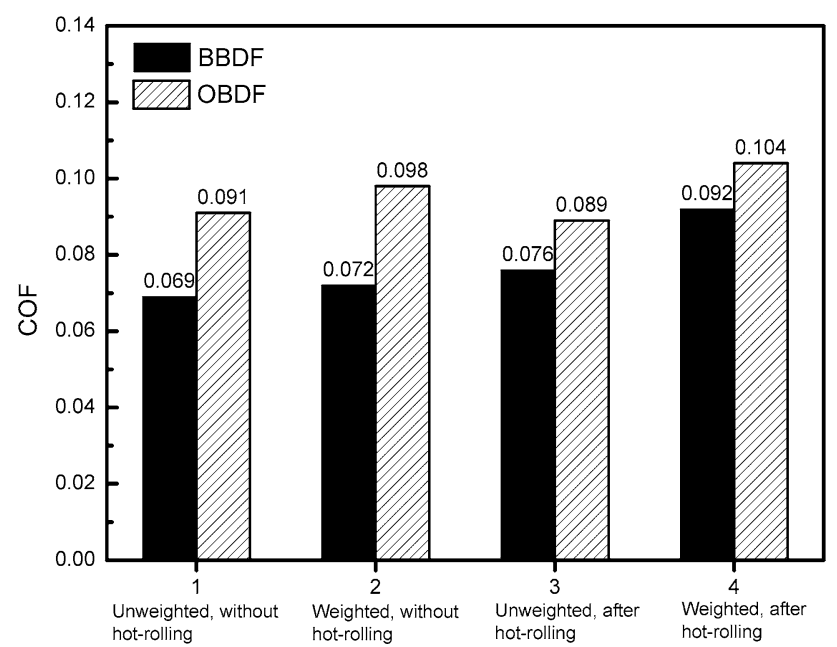

Fig. $7 \mathrm{COF}$ of BBDF and OBDF without/after hot-rolling

(Erhan et al. 2008; Mortier et al. 2010). Consequently, a physisorbed film formed by orientation arrangement of the ester molecules is obtained. A direct proof is the contact angle of biodiesel on the surface of G105 steel (Fig. 2). (2) Chemisorption. Most metal oxide surfaces are partially hydroxylated in the presence of water vapor. These hydroxylated surfaces can participate in hydrogen bonding either as a hydrogen-atom donor or as an acceptor. Thus, absorption of hydrogen-atom acceptors such as ester lubricants (or decomposition by-products such as alcohols and carboxylic acids at high temperature) leads to wear protection and friction reduction. Esters therefore tend to be more effective lubricants than non-polar oils. Generally, hydrogen bond is deemed to be relatively weak. As the load increasing and the temperature elevating, it may break down. However, under some special conditions (such as extreme pressure), esters can form tough chemisorption films. Hydrogen bond and Debye orientation force are considerably stronger than dipole (Van der Waals) interaction in these cases (Liang et al. 2004). (3) Lubrication of the absorption film. As mentioned, the absorption film comprising one or a few layers of biodiesel molecules is adhered closely on the steel. In other words, through the cohesive interaction between them, the molecules arrange directionally and make up a kind of "fence" structure spontaneously. During the friction process, the steel surfaces can be isolated by the "fence" and the friction between the two metal surfaces (or the friction between a metal surface and a rock surface) is converted into the friction between two biodiesel molecule films. Hence, the direct contact of the friction pair is avoided effectively and the COF decreases greatly because of good elasticity and smoothness of the film. For another thing, the film absorbed on the surfaces is difficult to be broken or fall off due to their strong wettability, which ensures the steady lubrication performance of the biodiesel.

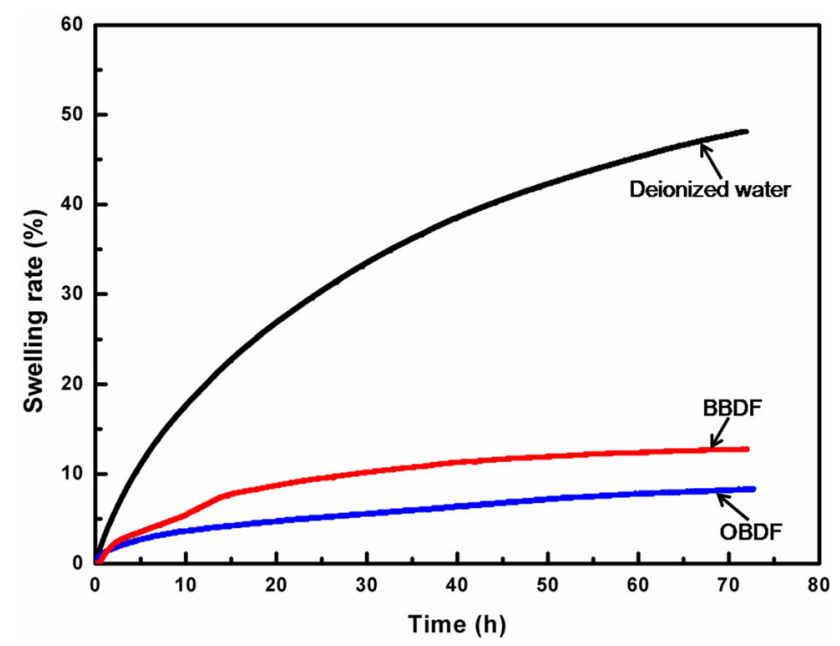

Fig. 8 Linear swelling rate-time curves for BBDF, OBDF and deionized water

\section{Shale inhibition ability}

In many cases, shale hydration is the prime cause of hole instability. Hence, the inhibition ability is a very important property for a drilling fluid. The linear swelling rate-time curves for BBDF, OBDF, and deionized water are revealed in Fig. 8. It shows that the swelling rates for BBDF and OBDF are both quite low (13.1\% for BBDF and $7.8 \%$ for OBDF, after $72 \mathrm{~h}$ ), while the deionized water makes the shale swell greatly (48.5\% after $72 \mathrm{~h}$ ). These results were caused by the difference of molecular structures of biodiesel, petrodiesel, and water. As known, polarities of biodiesel molecules are larger than those of petrodiesel molecules, for the existence of carbonyls in biodiesel. This means the interaction between biodiesel/shale is slightly stronger than that of petrodiesel/shale. On the other hand, as a polar liquid, water interacts with shale much more severe, leading to the significant shale swelling. In short, it can be considered that BBDF has a strong inhibition power which is slightly weaker than OBDF.

\section{Toxicity and biodegradability}

Table 8 gives the results of the ecotoxicity tests for BBDF and OBDF, demonstrating the absence of toxicity of BBDF. The ranking of toxicity for OBDF is Moderately Toxic. Figure 9 indicates that BBDF achieved more than $70 \%$ of degradation over 28 days, in contrast with $24.0 \%$ for OBDF. Biodiesel has no aromatic material and the structures of its molecules have low branching degrees. These enable BBDF to biodegrade rapidly. Briefly, as an environmental friendly drilling fluid, BBDF is nontoxic and its biodegradability is much higher than that of OBDF. 
Table 8 Ecotoxicity tests for BBDF and OBDF (both unweighted)

\begin{tabular}{|c|c|c|c|c|}
\hline Test drilling fluid & Test method & Test protocol & Result & Ranking \\
\hline \multirow[t]{4}{*}{ BBDF } & $72 \mathrm{~h} \mathrm{EC}_{50}$ & ISO 10253 & $3127.6 \mathrm{mg} / \mathrm{L}$ & Nontoxic \\
\hline & (Skeletonema costatum) & & & \\
\hline & $48 \mathrm{~h} \mathrm{LC}_{50}$ & ISO 14669 & $13254.4 \mathrm{mg} / \mathrm{L}$ & Nontoxic \\
\hline & (Arcatia tonsa) & & & \\
\hline \multirow[t]{4}{*}{ OBDF } & $72 \mathrm{~h} \mathrm{EC} 50$ & ISO 10253 & $18.1 \mathrm{mg} / \mathrm{L}$ & Moderately toxic \\
\hline & (Skeletonema costatum) & & & \\
\hline & $48 \mathrm{~h} \mathrm{LC}_{50}$ & ISO 14669 & $28.3 \mathrm{mg} / \mathrm{L}$ & Moderately toxic \\
\hline & (Arcatia tonsa) & & & \\
\hline
\end{tabular}

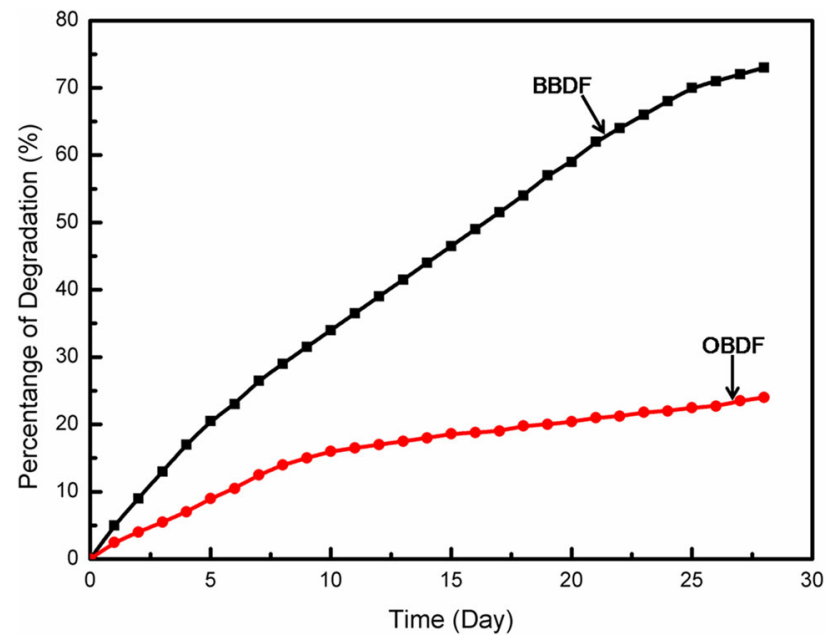

Fig. 9 Percentages of degradation of BBDF and OBDF over 28 days

\section{Emulsifier package for biodiesel-based drilling fluid}

Kinetic stability of the invert emulsion is a crucial property, since an emulsion which can remain homogeneous for a long time is the basis of reliable performances for a drilling fluid. So it is necessary to discuss the emulsifiers used in BBDF. The primary emulsifier selected in this work, Emulsifier 1, is the key part of the whole emulsifier package. It consists of several sorts of fatty alkanolamides produced from the waste cooking oil. The waste cooking oil was pretreated for purification firstly, and then reacted with monoethanolamine, or diethanolamine, or triethanolamine at a certain temperature and turns into the alkanolamides. A small amount of tall oil fatty acids are added into the alkanolamides as a cosurfactant. The primary emulsifier has alkyl chains similar to the biodiesel because the raw materials for producing them are same (both are waste cooking oil). This assures that the primary emulsifier has a great power to stabilize the biodiesel-based invert emulsion. The secondary emulsifier of the package is one kind of alkyl sulfonate, e.g., calcium dodecyl sulfonate. It can improve the emulsifying power of the primary emulsifier to some degree. The successful development of the novel emulsifier package provides a promising way to utilize the waste cooking oil comprehensively, as shown in Fig. 10. For one thing, rich sources of waste cooking oil can lower the cost of the emulsifier significantly, which may be a piece of good news for the drilling industry. For another, it provides a novel way of converting waste cooking oil to a useful chemical. Last but not least, it may promote further recovery and recycle for the waste, which has an environmental meaning.

\section{Economic analysis and prospect}

The successful development of BBDF provides a reliable option as a substitute for oil-based drilling fluids due to the continuous increase of the global biodiesel production. In 2000, the world biodiesel production was 213 million gallons (Licht 2008). This number rose to 1.71 billion gallons in 2006 (Licht 2012) and soared to breathtaking 6.29 billion gallons in 2013 (Guo et al. 2015). On the basis of such a rapid growth of global biodiesel production during the first 15 years of the new millennium, the abundance of sources is undoubtedly a substantial advantage of biodiesel over conventional ester base fluids for drilling. Also, the ever-emerging feedstock types which can be used to produce biodiesel are able to keep the global biodiesel supply stable.

A variety of supporting policies in many countries promoted the prosperity of the world biodiesel industry and lowered biodiesel price to some degree. Common policies include biodiesel production subsidies, biodiesel blend mandates, and tax incentives. For instance, in August 2012, the U.S. Senate Finance Committee announced to provide tax credits of $\$ 1$ per gallon for biodiesel production. Another example is Brazil, as one of the world's leaders of biodiesel production and sales, its government implemented the National Biodiesel Production and Application Plan in January 2005, which required from January 2008 the traditional diesel to be mixed with $2 \%$ biodiesel, and raising to $5 \%$ by January 2013 (Cheng et al. 2009). In 


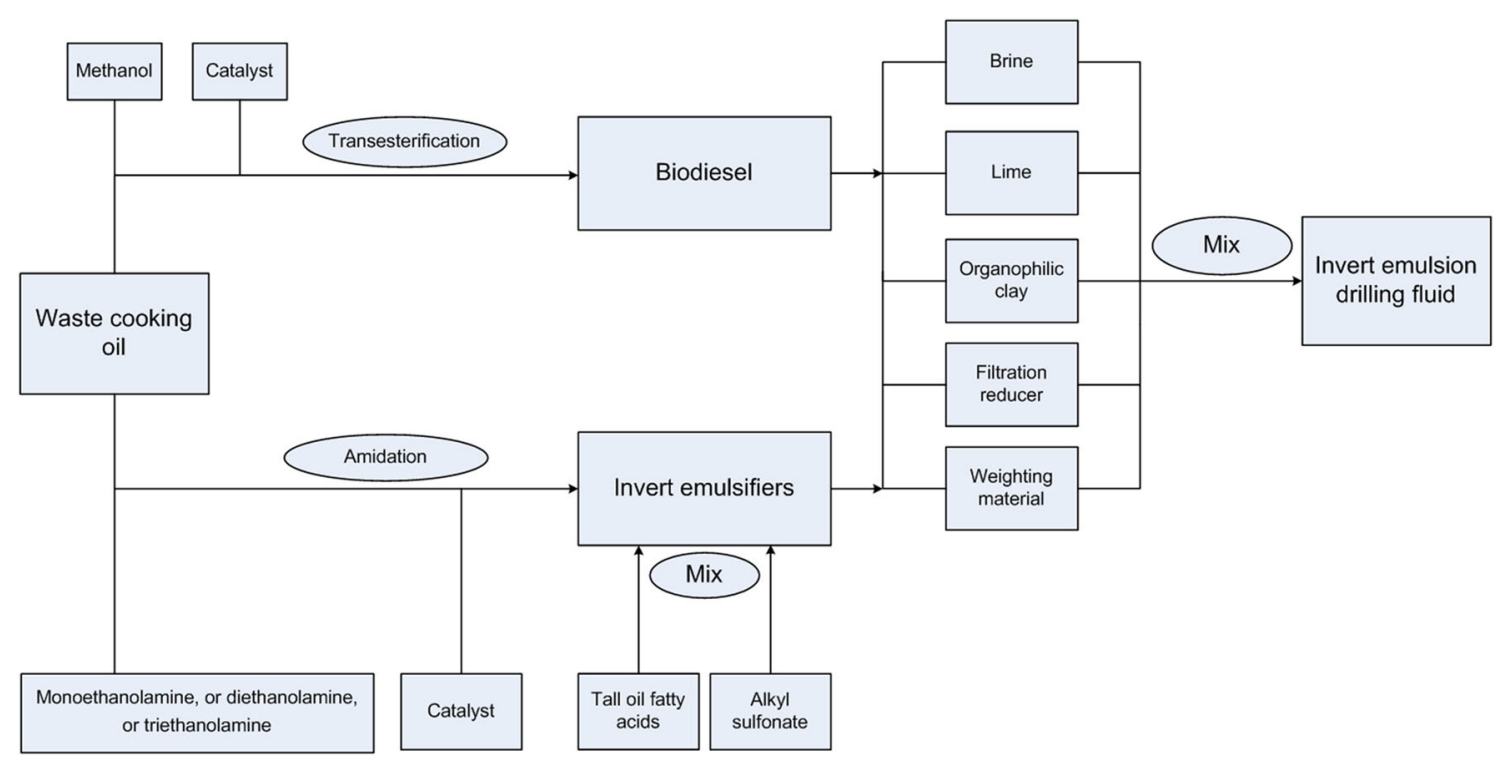

Fig. 10 A way to comprehensive utilization of waste cooking oil: to produce biodiesel and emulsifiers

2010, the ministry of finance of China and the state administration of taxation of China jointly issued a formal announcement, exclaiming that biodiesel produced from waste animal/vegetable oils should be exempted from the consumption tax (Ministry of Finance of China and State Administration of Taxation of China 2010). This lowered the biodiesel price by about $15 \%$ and dramatically stimulated the desire of the application of biodiesel in China. Before the submission of this paper, the price of petrodiesel (0\#) in China was approximately 5.54 ¥RMB/L, and that of biodiesel was $6.02 ¥ \mathrm{RMB} / \mathrm{L}$. Assuming that the additives used in BBDF are similar to those of OBDF (like this work mentioned), it can be roughly estimated that the formulating cost of BBDF is higher than that of OBDF by 5-15\%.

Although the formulating cost of BBDF is higher than OBDF, in view of the great environmental acceptability BBDF, the increase of total drilling cost caused by replacing $\mathrm{OBDF}$ with $\mathrm{BBDF}$ would be probably not that significant. As known, the regulations on ester-based drilling fluids are relatively looser than other non-aqueousbased drilling fluids. For example, the U.S. Effluent Guidelines proposed that the retention of drilling fluid on cuttings (ROC) for ester fluids should not be over $9.4 \%$ (by wet weight), while this limitation for internal olefin fluids is $6.9 \%$ (Friedheim et al. 2001; Klein et al. 2003). This implies that BBDF is easier to be treated and disposed than other non-aqueous-based drilling fluids, which makes it acceptable for drilling contractors. Moreover, as discussed above, the booming of the biodiesel industry and increasing supporting policies would hopefully make the cost of BBDF experience a further cut in the future. To summarize, BBDF is economically feasible as long as its eligible operational performances are ensured.

\section{Conclusions}

In this work, based on the stable emulsion, biodiesel produced from waste cooking oil was selected as the base fluid and a biodiesel-based drilling fluid (BBDF) system was prepared and evaluated. Several conclusions can be drawn as follows:

- The biodiesel selected is eligible for external phase of drilling fluid owing to its high flash point, acceptable viscosity, low toxicity, no fluorescence, and reliable storage stability.

- The electrical stability of BBDF is fine. The rheological parameters and filtration property of BBDF are acceptable for drilling at $120^{\circ} \mathrm{C}$. The tolerance limits for sea water and drilling solid are $10 \%$ (vol/vol) and $15 \%$ (wt/vol), respectively.

- The lubricity of BBDF is excellent, whether being hotrolled or not. BBDF is suitable to be used in extended reach drilling, directional drilling, or horizontal drilling.

- Shale inhibition ability of BBDF is slightly weaker than OBDF, although it is much stronger than water-based drilling fluid.

- BBDF belongs to nontoxic drilling fluid and its biodegradability is higher than that of OBDF.

- An effective emulsifier package produced from waste cooking oil was developed successfully. It provides a 
promising way of comprehensive utilization of the waste.

- BBDF is economically feasible because of the robust growth of the global biodiesel production, various supporting policies, and its low treatment cost.

- Evidently, biodiesel-based drilling fluid has a considerable value for further investigation. However, field tests should be conducted in order to validate the laboratory results of this drilling fluid system. This work will be conducted and reported in the future.

Acknowledgments The authors gratefully acknowledge the financial support from the Key Projects in the National Science and Technology Pillar Program during the Twelfth Five-year Plan Period of China (No. 2013BAB11800). The author would also like to thank Beijing LDS Technology Co. Ltd. for providing instrument support.

Open Access This article is distributed under the terms of the Creative Commons Attribution 4.0 International License (http:// creativecommons.org/licenses/by/4.0/), which permits unrestricted use, distribution, and reproduction in any medium, provided you give appropriate credit to the original author(s) and the source, provide a link to the Creative Commons license, and indicate if changes were made.

\section{References}

Amin RAM, Clapper DK, Norfleet JE, Otto MJ, Xiang T, Hood CA, Goodson JE, Gerrard DP (2010) Joint development of an environmentally acceptable ester-based drilling fluid. In: SPE 132693, Trinidad and tobago energy resources conference, Port of Spain, Trinidad, June 27-30

API (2005) API RP 13B-2, recommended practice for field testing of oil-based drilling fluids, 4th edn. Washington, DC

ASTM International (2002) ASTM D97-93, standard test method for pour point of petroleum products. Conshohocken, Pennsylvania

ASTM International (2009) ASTM D6751-08, standard specification for biodiesel FuelBlendStock (B100) for distillate fuels. Conshohocken, Pennsylvania

ASTM International (2010) ASTM D6371, standard test method for cold filter plugging point of diesel and heating fuels. Conshohocken, Pennsylvania

Becher P (1965) Emulsions: theory and practice. Reinhold Publishing Corporation, New York

Caenn R, Chillingar GV (1996) Drilling fluids: state of the art. J Petrol Sci Eng 14:221-230

Caenn R, Darley HCH, Gray GR (1988) Composition and properties of drilling and completion fluids, 5th edn. Gulf Professional Publishing, USA

Candler JE, Rushing JH, Leuterman JJ (1993) Synthetic-based mud systems offer environmental benefits over traditional mud systems. In: SPE 25993, SPE/EPA exploration and production environmental conference, San Antonio, Texas, March 7-10

Cheng Y, Lu Y, Yu SS (2009) Brazil's policies and measures taken in developing biodiesel. Sino-Global Energy 5:41-46

DeOliveira E, Quirino RL, Suarez PAZ, Prado AGS (2006) Heats of combustion of biofuels obtained by pyrolysis and by transesterification and of biofuel/diesel blends. Thermochim Acta 450:87-90
Erhan SZ, Sharma BK, Liu Z (2008) Lubricant base stock potential of chemically modified vegetable oils. J Agric Food Chem 56(19):8919-8925

European Committee for Standardization (2003) ECN EN14214, fatty acid methyl esters (FAME) for diesel engines-requirements and test methods, Brussels

Friedheim JE (1997) Second-generation synthetic drilling fluids. J Petrol Technol 49:724-728

Friedheim JE, Patel A (1999) Technical solutions for environmental problems: novel drilling formulations to minimize environmental impact. In: SPE 52741, SPE/EPA exploration and production environmental conference, Austin, Texas, March 1-3

Friedheim JE, Candler JE, Rabke SP (2001) New testing protocols and regulatory guidelines to promote further development of synthetic-based fluid technology. In: SPE 71435, SPE annual technical conference and exhibition, New Orleans, Louisiana, September 30-October 3

Guo MX, Song WP, Buhain J (2015) Bioenergy and biofuels: history, status, and perspective. Renew Sustain Energy Rev 42:712-725

Haas MJ, Michalski PJ, Runyon S, Nunez A, Scott KM (2003) Production of FAME from acid oil, a by-product of vegetable oil refining. J Am Chem Soc 80:97-102

ISO/TC (1999) ISO 14669, water quality-determination of acute lethal toxicity to marine copepods (Copepoda, Crustacea)

ISO/TC (2006) ISO/DIS 10253, Water quality-Marine algae growth inhibition test with Skeletonema costatum and Phaeodactylum tricornutum

James R, Navestad P, Schei T, Geddes T, Nelson G, Webster D (1999) Improving the working environment and drilling economics through better understanding of oil based drilling fluid chemistry. In: SPE-57551, SPE/IADC middle east drilling technology conference, Abu Dhabi, United Arab Emirates, November 8-10

Jason M (2007) Thixotropy and yield stress behavior in drilling fluids. In: AADE-07-NTCE-37, 2007 AADE national technical conference and exhibition, Houston, Texas, April 10-12

Klein AL, Aldea C, Bruton JR, Dobbs WR (2003) Field verification: invert mud performance from water-based mud in Gulf of Mexico Shelf. In: SPE-84314, SPE annual technical conference and exhibition, Denver, Colorado, October 5-8

Knothe G (2006) Analyzing biodiesel: standards and other methods. J Am Chem Soc 83:823-833

Knothe G (2008) "Designer" biodiesel: optimizing fatty ester composition to improve fuel properties. Energy Fuels 22:1358-1364

Knothe G, Steidley KR (2005) Kinematic viscosity of biodiesel fuel components and related compounds. influence of compound structure and comparison to petrodiesel fuel components. Fuel 84:1059-1065

Li W, Huang JJ, Liu YX, Luo XS, Li CX (2005) The influence of drilling fluid additives on the formation of gas hydrate. J Southwest Petrol Univ 27:62-64

Liang H, Totten GE, Webster GM (2004) Lubrication and tribology fundamentals. CRC Press, USA

Licht FO (2008) World ethanol and biofuels. Report 7(2):29

Licht FO (2012) World ethanol and biofuels. Report 10(14):281

Ministry of Finance of China and State Administration of Taxation of China (2010) Pure biodiesel produced from waste animal/ vegetable oil shall be exempt from the consumption tax. http:// gz.mof.gov.cn/lanmudaohang/zhengcefagui/201102/t20110212 447510.html

Mohibbe Azam M, Waris A, Nahar NM (2005) Prospects and potential of fatty acid methyl esters of some non-traditional seed oils for use as biodiesel in India. Biomass Bioenergy 29:293-302

Mortier RM, Fox MMF, Orszulik ST (2010) Chemistry and technology of lubricants, 3rd edn. Springer, Germany 
Moser BR (2011) Biodiesel production, properties, and feedstocks. Biofuels, Springer, New York

Neff JM (2005) Composition, environmental fates, and biological effect of water based drilling muds and cuttings discharged to the marine environment: a synthesis and annotated bibliography. In: Petroleum environmental research forum (PERF). American Petroleum Institute, Washington, DC

OECD Chemical Group (1993) Ready biodegradability: Closed Bottle Test. Method 301D, OECD revised guidelines for tests for ready biodegradability, Paris, France

Peresich RL, Burrell BR, Prentice GM (1991) Development and field trial of a biodegradable invert emulsion fluid. In: SPE 21935, SPE/IADC Drilling Conference, Amsterdam, Netherlands, March 11-14

Predojević ZJ (2008) The production of biodiesel from waste frying oils: a comparison of different purification steps. Fuel $87: 3522-3528$
Sinha S, Agarwal AK, Garg S (2008) Biodiesel development from rice bran oil: transesterification process optimization and fuel characterization. Energy Convers Manag 49:1248-1257

Srivastava PK, Verma M (2008) Methyl ester of Karanja oil as an alternative renewable source energy. Fuel 87:1673-1677

Wang MS, Sun MB, Shang HY, Fan SL, Liu MQ, Liu FP (2012) Biodiesel-based drilling fluids. In: SPE 155578, IADC/SPE Asia Pacific Drilling Technology Conference and Exhibition, Tianjin, China, July 9-11

Yan JN (2001) Drilling fluid technology. China University of Petroleum Press, Shandong

Yang J, Xu TT, Wu XX, Pan XY, Hou RX (2013) The studies of biodiesel drilling fluids. Drill Fluid Complet Fluid 30:15-18

Zhang Y (1998) Review on the development of synthetic-based drilling fluids. Drill Fluid Complet Fluid 15:28-32 